\title{
этнология
}

\section{Буддийская символика в системе калмыцких тамг}

\section{Дарья Бадмаевна Гедеева ${ }^{1}$, Гантулга Д. ${ }^{2}$}

\author{
${ }^{1}$ Калмыцкий научный центр РАН (д. 8, ул. им. И. К. Илишкина, 358000 Элиста, Рос- \\ сийская Федерация) \\ кандидат филологических наук, ведущий научный сотрудник \\ iD 0000-0002-8735-9184. E-mail: dgedeeva@mail.ru
}
${ }^{2}$ Ховдский государственный университет (г. Ховд, Ховдский аймак, Монголия) кандидат культурологии, заведующий кафедрой дизайна iD 0000-0002-8468-8548. E-mail: Gantulga9913@gmail.com

\author{
(С) КалмНЦ РАН, 2020 \\ С Гедеева Д. Б., Гантулга Д., 2020
}

\begin{abstract}
Аннотация. Введение. Калмыки уже много столетий исповедуют буддизм, символика которого естественным образом бытует в сфере материальной и духовной культуры народа. В данной статье рассматриваются буддийские знаки, отразившиеся в изображениях тамг, маркерах калмыцких родов. Тамгами, как и все кочевые народы, калмыки клеймили родовой и семейный скот, в основном лошадей и верблюдов. Несмотря на то, что традиция клеймения скота у калмыков угасла в советское время, изображения тамг сохранились в народной памяти и продолжают оставаться символами их родовой принадлежности. Цель статьи - выявление и описание знаков с сакральной тематикой в системе калмыцких тамг. Научная ценность исследования состоит в том, что выявленный и описанный материал необходим для создания картины развития материальной и духовной культуры калмыков. Данная тема исследования остается малоизученной, что делает ее весьма актуальной и востребованной. Материалами исследования явились полевой материал авторов и материал, собранный студентами факультета калмыцкой филологии и культуры Калмыцкого государственного университета (в настоящее время - Институт калмыцкой филологии и востоковедения КалмГУ им. Б. Б. Городовикова) в комплексных экспедициях по районам Калмыкии в 1971-1990 гг. Результаты исследования свидетельствуют о частом употреблении в системе калмыцких тамг буддийской символики, что является показателем отношения калмыков к ним как к сакральным оберегам, защищающим их скот, основное богатство скотоводов.
\end{abstract}

Ключевые слова: тамга, клеймение, буддизм, символика, изображение, традиция, род, народ, этнический маркер

Благодарность. Исследование выполнено при поддержке РФФИ, проект № 19-51244002 «Народное декоративно-прикладное искусство ойратов Монголии и калмыков России: общее и особенное в сравнительно-сопоставительном анализе». 
Для цитирования: Гедеева Д. Б., Гантулга Д. Буддийская символика в системе калмыцких тамг // Монголоведение. 2020. № 1. С. 142-153. DOI: 10.22162/2500-15232020-1-142-153.

UDC 39

\title{
Buddhist Symbolism in the System of Kalmyk Tamgas
}

Daria B. Gedeeva ${ }^{1}$, Gantulga D. ${ }^{2}$

${ }^{1}$ Kalmyk Scientific Center of the RAS (8, Ilishkin St., Elista 358000, Russian Federation)

Cand. Sc. (Philology), Leading Research Associate

iD 0000-0002-8735-9184. E-mail: dgedeeva@mail.ru

${ }^{2}$ Khovd State University (Jargalant Sum, Khovd Province, Mongolia)

Ph.D. (Cultural Studies), Head of Department of Design

iD 0000-0002-8468-8548. E-mail: Gantulga9913@gmail.com

(C) KalmSC RAS, 2020

(C) Gedeeva D. B., Gantulga D., 2020

\begin{abstract}
Introduction. The Kalmyks had converted to Buddhism centuries ago, and its symbolism is naturally integral to material and spiritual culture of the ethnos. The article examines Buddhist symbols used in tamgas - Kalmyk clan markers that served to brand family or clan livestock, primarily horses and camels. Despite the tradition died away in the Soviet era, tamgas are still venerated, remaining symbols of clan identity. Goals. The paper reveals and describes sacred symbols incorporated into the system of Kalmyk tamgas. The materials are most essential to restore the developmental panorama of ethnic material and spiritual culture, which stays understudied and, thus, topical enough. Materials. The work analyzes field data collected by the author and students of the Gorodovikov Kalmyk State University during comprehensive research expeditions to Kalmykia's districts between 1971 and 1990. Results. The study attests to quite a wide distribution of Buddhist symbols among Kalmyk tamgas, which indicates that people did revere them as sacred averters capable of protecting livestock, the herders' main treasure.
\end{abstract}

Keywords: tamga, livestock branding, Buddhism, symbolism, picture, tradition, clan, ethnos, ethnic marker

Acknowledgements: The reported study was funded by RFBR, project no. 19-512-44002 'Folk Decorative and Applied Arts of Mongolian Oirats and Russian Kalmyks: Common and Specific Features in a Comparative Perspective'.

For citation: Gedeeva D. B., Gantulga D. Buddhist Symbolism in the System of Kalmyk Tamgas. Mongolian Studies. 2020. No. 1. Pp. 142-153. DOI: 10.22162/2500-1523-2020-1142-153.

\section{Введение}

Тамга как знак клеймения имеет древнее происхождение, вероятно, еще с тех времен, когда появилась родовая и частная собственность на скот. Передаваясь из поколения в поколение, семейно-родовая тамга изменяла свой рисунок, основной знак приобретал дополнительные элементы, расширяя тем 


\section{Монголоведение • Mongolian Studies • $2020 \bullet$ T. 12 • №1}

самым круг символов этнической принадлежности. Основу многих знаков составляли простые геометрические фигуры, такие как линия, треугольник, угол, круг, квадрат, что и явилось, вероятно, причиной совпадения родовых знаков у многих народов.

Известно, что тамги у разных народов совпадают по начертанию, но имеют свои названия, в зависимости от той картины мира, которая им свойственна. Так, знаки свастики и креста встречаются повсеместно и как знаки собственности, и как орнаментика у народов Европы и Азии, и имеют различные наименования и значения [Городцов 1923: 282]. В результате дальнейшей эволюции тамговые знаки стали употребляться в области геральдики, религиозных сакральных символов, печатей, орнаментики в бытовых предметах и т. д. Об этом свидетельствуют сохранившиеся до наших дней знаки на старинных знаменах, гербах, монетах, оружии, надгробных плитах, глиняных горшках, вышивках.

Если говорить об употреблении тамги у монгольских народов, то следует сказать, что в современной Монголии традиция применения древних знаков не прерывалась, и в настоящее время тамги активно используются животноводами при таврении лошадей и верблюдов. У калмыков же она ушла в историческое прошлое вместе с коллективизацией сельского хозяйства в советское время. Однако им родовые тамги известны по воспоминаниям старшего поколения, архивным материалам, книгам путешественников и исследованиям современных этнографов. Так, в XIX в. в своих трудах о быте и нравах калмыцкого народа о них писали П. И. Небольсин и К. И. Костенков [Небольсин 1852: 13-14; Костенков 1868: 167-171].

Из современных исследователей в контексте изучения состава и происхождения калмыков тамговые знаки описывали по архивным документам и полевым материалам калмыцкие этнографы Г. О. Авляев, А. Г. Митиров, Э. П. Бакаева, Т. И. Шараева [Митиров 1998; Авляев 2002; Бакаева 2016; Шараева 2017].

Как объект материальной культуры тамги были рассмотрены С. Г. Батыревой [Батырева 2006: 91-93]. Наибольшее количество рисунков калмыцких тамг было введено в научный оборот Д. Б. Гедеевой [Гедеева 2003a: 254-260; Гедеева 2003б: 272-275].

Несмотря на это, калмыцкие тамги остаются до конца не выявленными и не изученными, а известные работы имеют обзорный характер. Поэтому данную статью мы посвятили более подробному описанию группы знаков, объединенных нами тематически.

\section{Основная часть}

К сожалению, до настоящего времени нет специальной литературы, в которой бы освещалась калмыцкая традиция таврения, а именно: как проходил сам процесс нанесения знака, какими обрядами и ритуалами сопровождалось это действие, выбирался ли благоприятный день, в каком возрасте лошадям наносили тавро, как лечились ожоги на шкуре у животных, как делались железные трафареты тавра и как их хранили и т. д. Эти вопросы хорошо освещены монгольскими исследователями в научной литературе, посвященной таврению монгольских лошадей и верблюдов в древней и современной традициях [Чойсамба 1974; Баасансүх 2008; Саруулбуян, Даваасамбуу 2008; Пэрлээ 2012]. 


\section{Этнология}

Многочисленный скот, имеющийся у монголов в частной собственности, не дает угаснуть традиции помечать скот старинными тамгами. В этой связи представляется необходимой поисковая и исследовательская работа на территории Западной Монголии для выявления ойрат-калмыцких корней этой животноводческой традиции, а также сбор материала в российских архивах и у информантов старшего поколения в Калмыкии, что в итоге поможет создать общую картину бытования этой традиции у калмыков и даст возможность составить каталог калмыцких тамг с указанием их родовой принадлежности.

Для данного исследования мы использовали в большей степени материал, собранный студентами факультета калмыцкой филологии и культуры Калмыцкого государственного университета (в настоящее время - Институт калмыцкой филологии и востоковедения Калмыцкого государственного университета им. Б. Б. Городовикова) в комплексных экспедициях по районам Калмыкии в 1971-1990 гг.

Выявленные названия и изображения калмыцких тамг, передавая формы объектов живой и неживой природы, отражают фауну местности, материальную и духовную культуру народа. Так, встречаются изображения, символизирующие представителей степной фауны (моһa 'змея', оон 'сайгак-самец'), предметы быта (хәәч 'ножницы', сам 'гребень', түлкүр 'дверной крючок’), элементы кибитки (харач 'обруч для верхнего отверстия кибитки', цุаһрг 'крестовина обруча'), орудия труда (көрә 'пила', маля 'плеть'), орудие войны (балт 'секира', сумта нумн 'лук со стрелой'), буддийскую символику и предметы культа (жиндмн 'чиндамани', жсунгру 'свастика', очр 'ваджра' и т. д.), китайские письменные знаки.

В данной статье нами описываются тамги, представляющие собой сакральные символы, пришедшие в культуру калмыков вместе с буддизмом. Буддизм, исповедуемый калмыками, оказал большое влияние на духовную культуру народа. Свидетельством этого является национальное письмо, созданное буддийским монахом и просветителем, богатая литература по буддийской философии на калмыцком языке, устное народное творчество, пронизанное буддийской темой и т. д. К материальным объектам, отражающим буддийскую культуру, следует отнести архитектуру в виде зданий буддийских монастырей и других культовых объектов, ритуальные предметы, изображения божеств. К сожалению, материальные свидетельства буддийского влияния на культуру народа оказались недолговечными из-за антирелигиозной политики государства в советский период. До наших дней сохранилось малое количество того, что было в прошлые столетия.

Калмыцкие тамги, отражающие буддийские символы, представляют собой довольно многочисленную группу. Один из наиболее часто встречающихся знаков - изображение чиндамани (рис. 1) ${ }^{1}$ [ПМ 1971-1990]. В индуистской и буддийской мифологиях чиндамани - это магический камень (кристалл), исполняющий желания, символизирует духовные сокровища, которыми может овладеть просветленный ум.

На иконах-тханках чиндамани изображают на спине белого коня. Роберт Бир, художник и исследователь тибетского и непальского искусства, в своем

\footnotetext{
${ }^{1}$ Рисунки выполнены нами. - Д. Г.
} 
труде, посвященном тибетским символам и орнаментам, об этом камне пишет следующее: «Его сияние освещает тьму ночи; оно охлаждает, когда стоят жаркие дни, и согревает, когда холодно; оно вызывает дождь или открывает источник, если испытываешь жажду; оно осуществляет все, чего желает его обладатель; оно контролирует нагов, предотвращая наводнения, град и проливной дождь; драгоценность испускает разноцветные лучи света, которые исцеляют омрачения ума; ее сияние исцеляет все болезни у тех, кто находится в пределах целительного ореола; она предохраняет от преждевременной смерти, гарантируя то, что смерть от естественных причин будет происходить в роду в благоприятной последовательности — сначала дед, потом отец и потом сын» [Бир 2011: 177].

Тамги чиндамани у калмыков имеют различные варианты изображений: горизонтальные, вертикальные, с дополнительными элементами. Санскритское название их в калмыцком языке подверглось фонетическим изменениям, и название таких тамг произносятся как жсиндмн, зиндмн, зидмн, диндн.
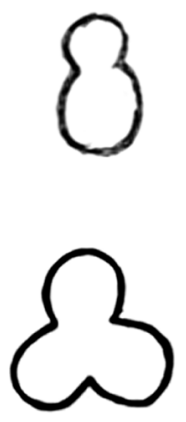
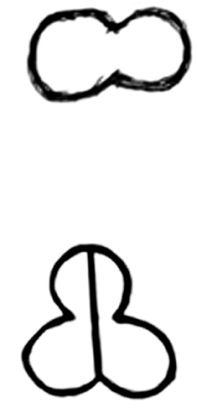
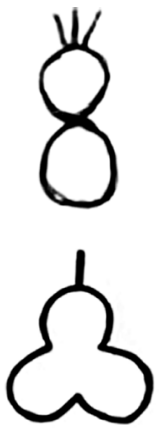
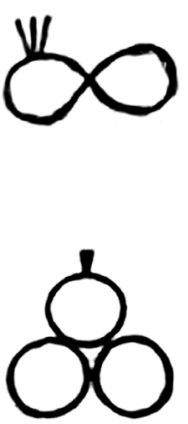

Puc. 1. Тамги с различными изображениями чиндамани

[Fig. 1. Tamgas depicting the cintāmani]

Очень популярна была тамга с изображением свастики - джунгру или зунгру (рис. 2). Знак представляет собой крест с загнутыми под прямым углом концами, направленными либо по ходу солнца, либо против. Как было сказано выше, свастика является одним из самых древних и широко распространённых графических символов. У многих народов мира она изображена на предметах быта, одежде, оружии, знамёнах и гербах, в храмах и т. д. Об этом хорошо сказано Робертом Биром: «Свастика (санскр. svastika) - символ, встречающийся во многих культурах и цивилизациях. Она появляется на египетской, троянской, римской, тевтонской и кельтской каменной резьбе; как символический узор у американских индейцев по всей Северной, Центральной и Южной Америке; в персидском, центральноазиатском, индийском, китайском, японском искусстве. В Древней Греции свастика была известна как „греческий крест“, или гаммадион, или свастика, стала символом Христа как „краеугольного камня Храма, или Церкви““. Подобный символизм встречается в буддийском искусстве, где свастика представляет стабильность элемента земли» [Бир 2011: 376].

У калмыков она использовалась также часто и не только в стенах монастырей. В первые годы советской власти джунгру (зунгру) как национальный символ вместе с пятиконечной звездой была эмблемой областной калмыцкой газеты, использовалась и в других общественно-политических мероприятиях и местах. 


\section{Этнология}

В системе калмыцких тамг изображение знака джунгру (зунгру) имеет несколько вариантов. Чаще концы свастики традиционно загнуты по часовой стрелке, но некоторые изображения имеют не обычную для себя конфигурацию: с опущенными вниз или поднятыми вверх концами горизонтальной линии, с повернутыми одновременно вправо или влево концами вертикальной линии, с кругом в центре.

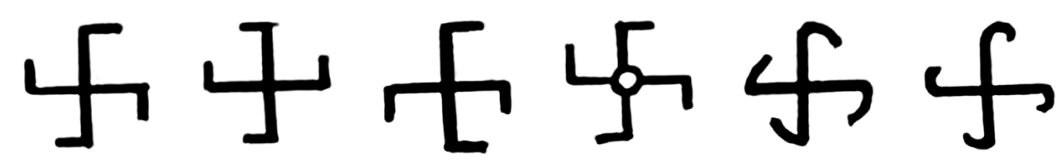

Puc. 2. Тамги в виде свастик различной конфигурации

[Fig. 2. Tamgas depicting swastikas]

Среди калмыцких тамг встречается также и номин күрд - изображение колеса с восемью спицами, символизирующего Учение Будды (рис. 3). Колесо в Индии было известно с древнейших времен как символ власти, созидания, солнца. В буддизме оно стало обозначать «колесо дхармы». Три составляющих колеса - обод, ступица, спицы - символизируют три аспекта буддийского учения: концентрацию, этику, мудрость. Восемь спиц символизируют Восьмеричный Благородный Путь Будды. Вращение колеса символизирует проповедь, изложение Учения Будды для спасения всех живых существ. В буддизме говорится о трех поворотах колеса Учения как о трех великих проповедях Будды.

В системе калмыцких тамг встречаются варианты этого символа: со ступицей и без ступицы, с восемью спицами и шестью.
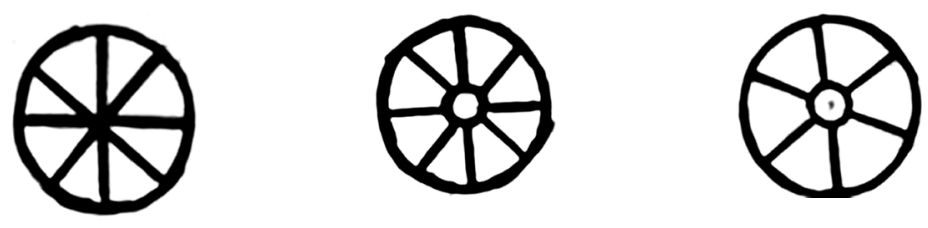

Puc. 3. Тамги в виде «Колеса Учения»

[Fig. 3. Tamgas depicting the Dharma Chakra]

Следующий буддийский символ, встречающийся в системе калмыцких тамг, называется туңмл (тумhл), известный в буддизме с тибетским названием гакиль, который переводится как 'завиток радости' (рис. 4). Три завитка его символизируют Три Драгоценности - Будду, Дхарму и Сангху - и победу над тремя ядами: неведением, страстью и гневом. Четыре завитка символизируют Учение Будды о Четырёх благородных истинах [Бир 2016: 37 ].

В рисунке калмыцких тамг эти завитки находятся как в круге, так и без круга. Этнограф П. И. Небольсин, находясь в командировке от Русского Географического общества в Хошеутовском улусе, описал значения некоторых калмыцких родовых тамг, в частности и данную разновидность тамги: «,Тунмыле в кругу есть тоже часть религиозных предметов. Круг означает круглый низенький сосуд, употребляемый при домашнем и при общественном бого- 
служении. В этот сосуд насыпается зола, и в ней выдавливается изображение, именующееся тунмылом < ..> В ямки, образовавшиеся от выдавливанья этой формы, насыпается благовонная трава, бакаутовое дерево и разные курения в порошках. В известные праздники благовония зажигаются и ставятся перед бурханами» [Небольсин 1852: 13].
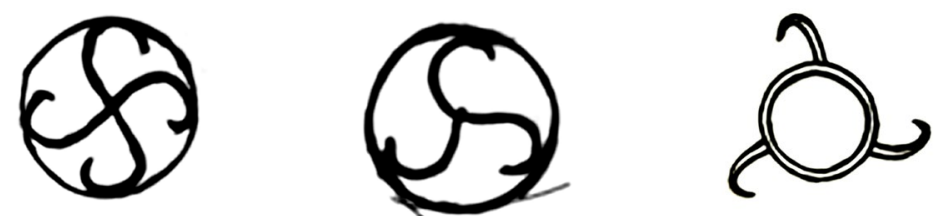

Puc. 4. Тамги в виде знака «тунгмыл»

[Fig. 4. Tungmyl tamgas]

При клеймении лошадей калмыки также использовали знак ваджры очр (скр. ваджра, тиб. дордже), символизирующий несокрушимое, недвижимое, неизменное и неделимое состояние просветления (рис. 5). Ваджра в буддизме имеет качества «несокрушимости бриллианта, непреодолимую мощь молнии и неразделимую прозрачную ясность пустого пространства» [Бир 2011: 256]. Среди выявленных нами рисунков калмыцких тамг под названием очр встречается несколько видов изображений: три овальных круга, перевернутый трезубец, кончик стрелы и вертикально расположенные два круга, соединенные по вертикали стержнем. Только один рисунок напоминает ваджру. Кончик стрелы, возможно, символизирует острие молнии, трезубец напоминает верхнюю часть ваджры, а три листика больше похожи на знак чиндамани.

У монгольских скотоводов используется подобная тамга с тремя листьями, называемая «цэцэг чандамань» [Чойсамба 1974: 67]. Такое несоответствие символов их названиям в системе тамг свидетельствует лишь о том, что работа по выявлению необходимой информации проводилась мало и несистематично. К сожалению, свидетелей калмыцкой традиции клеймения скота родовой тамгой уже трудно найти.
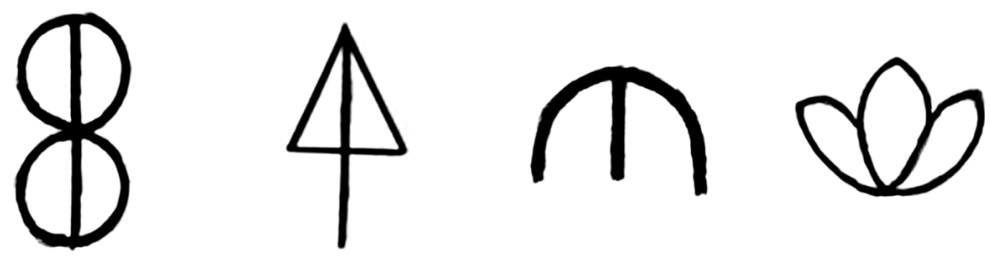

Puc. 5. Тамги под названием «очр» [ПМ 1971-1990].

[Fig. 5. Ochir tamgas

Тамга даризг (рис. 6) также имеет отношение к буддизму. Это тибетское название означает квадратные флажки пяти цветов с молитвенными текстами, напечатанными при помощи деревянной матрицы. Вывешивались они на вершинах деревьев, горы, крышах домов и храмов для того, чтобы молитвы были разнесены ветром. Делается это для устранения препятствий, привлечения благополучия, обретения добродетели, поскольку ассоциируются с 


\section{Этнология}

победой учения Будды над смертью, невежеством, негативными аспектами этого мира.

Разновидностью даризг являются ки мөрн (тиб. лунгта) 'конь ветра', на которых изображен конь, несущий на спине драгоценность чиндамани. Согласно буддийским представлениям, лошадь мчится как ветер в небесах без устали, символизируя жизненную силу человека и принося благополучие, удачу и процветание.

Описывая быт астраханских калмыков, русский этнограф И. А. Житецкий пишет о даризик, которые он видел в храмовых кибитках. Но здесь речь идет не о маленьких флажках, развешиваемых на ветру, а об иконах (тиб. тханка) с изображением божеств: «Второй вид священных изображений - это живописные изображения бурханов на четыреугольных кусках материи - „дарцик“, род хоругвей. Вверху „дарцик“ прикрепляется к древку, на которое он наматывается и хранится при перекочевке и в непраздничное время в ящиках; во время же праздников „дарцик’и“ развешиваются везде по стенам „хурля-кгер“, а самые большие из них привешиваются даже к „унинам“ и вывешиваются в средине кибитки. Величина „дарциков““ самая различная: от $1 \frac{1}{2}$ арш. до сажени и даже больше. < ..> Все ,дарцик'и“ рисуются красками, золотом и серебром, но встречаются ,дарцик'и“ бурхана Майдри, которые вышиваются шелком, золотом и серебром. Вышиванье производится калмыцкими женщинами (главным образом девушками и вдовами), требуют много времени и стоит дорого» [Житецкий 1893: 44-45]. Тамга под таким названием могла символизировать как маленький флажок, так и тханку с изображением божества. Еще одно значение слова дариг, вероятно, переносное, мы находим в Калмыцко-русском словаре А. А. Позднеева — «бумажный змей» [Позднеев 1911: 213].

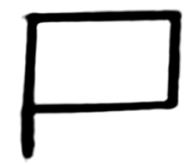

Рис. 6. Тамга «дарцг» [ПМ 1971-1990]

[Fig. 6. Dartsg tamgas]

Тамгами калмыки метили не только скот, но и некоторые предметы, в частности кирпичи, которые использовались при строительстве буддийских храмов. В научной литературе уже неоднократно описывался рисунок натянутого лука со стрелой (нум сумн) на кирпичах Хошеутовского хурула, единственного сохранившегося памятника калмыцкого зодчества начала XIX в. (рис. 7) [Мезенцев 1969: 25; Борисенко, Мошулдаев 1989: 6]. Данный знак представлял собой родовую тамгу нойонов Тюменей, которые построили этот величественный буддийский храм на берегу Волги по подобию Казанского собора в Петербурге, напоминающего в плане натянутый лук [Борисенко, Мошулдаев 1989: 6].

Натянутый лук со стрелой в буддизме также имеет свое сакральное значение, о котором пишет Роберт Бир, исследуя изображения божеств: «Лук и стрелы - это атрибуты многих божеств ваджраяны, чаще всего они встречаются в паре как отдельные принадлежности правой и левой рук. Лук обычно 
держится в левой руке мудрости, а стрела — в правой руке метода. <..> Подобным образом, когда лук рисуется с натянутой тетивой и со стрелой в позиции готовности к выстрелу, если тетива натянута правой рукой, это символизирует священную и спонтанную активность мудрости и метода, нацеленную точно в сердце врага (символизирующее дхармакаю). Здесь лук символизирует триумф в трех мирах, а стрела метафорически пронзает ложные воззрения, таких как различные предрассудки и беспорядочные мысли» [Бир 2011: 294].

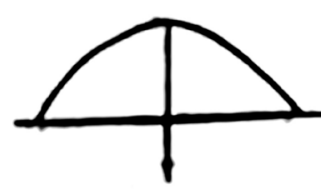

Рuc. 7. Тамга на кирпичах Хошеутовского хурула

(Астраханская область)

[Fig. 7. Tamga on bricks of Khosheutovsky Temple (Astrakhan Oblast)]

Старые храмы разрушались, и из строительных материалов строились клубы, библиотеки, агитпункты и т. д. Так из материалов бывшего Бергутинского хурула, который был разрушен в 1930-е гг., в пос. Джалыково Лаганского района был построен магазин. В 1992 г. он был переделан под молельный дом. Строителями, осуществлявшими ремонт, были обнаружены старые кирпичи, помеченные тамгой в виде буддийского символа - сар девскртә нарн 'солнца и луны' (рис. 8) [Манджиев 2020]. Это буддийский символ, имеющий глубокий философский смысл: «Растущая луна символизирует устремленность к пробуждению и прибывание бодхичитты. Солнечный диск символизирует мудрость и пустоту. Союз солнца и луны представляет вместерождённость метода и мудрости, или относительной и абсолютной бодхичитты» [Бир 2011: 140]. Этот символ используется как навершие буддийских храмов и ступ, которые можно увидеть уже в современной Калмыкии.

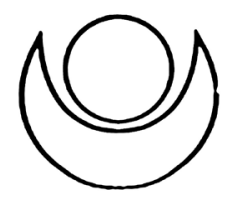

Puc. 8. Тамга на кирпичах Джалыковского хурула

(Лаганский район, Калмыкия)

[Fig. 8. Tamga on bricks of Dzhalykovo temple

(Lagansky District, Republic of Kalmykia)]

Тамгу под названием бу 'амулет' также можно отнести к предметам буддийской культуры. Так, об этом обереге в XIX в. писал Житецкий: «Средство, получаемое также от представителей религии, это „бу“, которое не столько лечит, сколько предохраняет от болезней и имеет характер талисмана. Гелюнг, к которому калмыки обратились бы за „бу“, пишет на бумажке священные изречения, зашивает в материю и надевает на шею пациенту, и с того момента „бу“ уже не снимается. Видов „бу“ много - есть „бу“ от болезни, „бу“ - от испуга, „бу“ - от грозы и пр.; но только „цакилган“ или „цаклаган бу“ от грозы может 


\section{Этнология}

принадлежать не лично одному лицу, а всей семье, и потому хранится в кибитке наряду и вместе с другими бурханами» [Житецкий 1893: 29].

Обычно сакральный текст зашивают в тряпочный конверт квадратной формы, реже - треугольной формы.

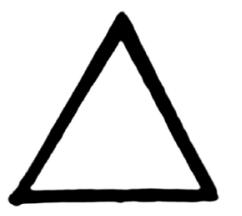

Puc. 9. Тамга «бу»

[Fig. 9. Bu tamga]

\section{Заключение}

Исследование показывает, что буддийская символика была широко распространена в системе калмыцких тамг. Причиной такой популярности могло быть особое отношение к ним как к сакральным оберегам, защищающим, по народным представлениям, скот. Думается, что такими знаками в большей степени клеймился скот буддийских монастырей и калмыцких князей, поскольку простолюдины держали определенные табу, моральные запреты по отношению к монастырям, монахам, культовым предметам как к священным вещам, требующим особого уважения и почитания. Символы, как нам представляется, не являются исключением из этого. Возможно, одной из мотиваций использования буддийских символов могло быть пожелание животному хорошего перерождения.

\section{Полевой материал}

ПМ 1971-1990 - экспедиционные материалы, собранные студентами факультета калмыцкой филологии и культуры Калмыцкого госуниверситета (ныне - Института калмыцкой филологии и востоковедения КалмГУ им. Б. Б. Городовикова).

Манджиев 2020 - Информант Манджиев Андрей Кекшинович. Полевой материал автора. Запись 2020 г.

\section{Author's Field Data}

[Expeditionary Materials Collected by Students of the Gorodovikov Kalmyk State University: 1971-1990]. (In Russ. and Kalm.)

Informant: Andrei K. Mandzhiev. Rec. of 2020. (In Russ. and Kalm.)

\section{Литература}

Авляев 2002 - Авляев Г. О. Происхождение калмыцкого народа. 2-е изд., перераб. и испр. Элиста: Калм. кн. изд-во, 2002. 325 с.

Бакаева 2016 - Бакаева Э. П. Знаки принадлежности: тамги ойратов Монголии и калмыков // Трансграничная культура: очерки сравнительно-сопоставительного исследования традиций западных монголов и калмыков: Монография / Э. П. Бакаева, К. В. Орлова, Д. Н. Музраева и др. Элиста: КалмНЦ РАН, 2016. С 122-129.

Баасансүх 2008 - Баасансүх Я. Монгол үндэстний овгийн тамга эдүгээд уламжлагдсан нь (= Продолжение традиции монгольской родовой тамги в настоящее время). Улаанбаатар: «Адмон» хэвлэлийн компани. 2008. 72 х.

Батырева 2006 - Батырева С. Г. Народное декоративно-прикладное искусство калмыков XIX - начала XX в. Элиста: НПП «Джангар», 2006. 160 с. 
Бир 2011 - Бир Р. Энциклопедия тибетских символов и орнаментов. Серия «Самадхи» / Роберт Бир; пер. с англ. Л. Бубенковой. М.: Ориенталия, 2011. 428 с.

Бир 2016 - Роберт Бир. Тибетские буддийские символы: справочник. Текст и илл.: Роберт Бир; пер. с англ. Л. Бубенковой. М.: Ориенталия, 2016. 336 с.

Борисенко, Мошулдаев 1989 - Борисенко И., Мошулдаев Б. Хошеутовский хурул. Элиста: Калм. кн. изд-во, 1989. 27 с., ил.

Гедеева $2003 \mathrm{a}-$ Гедеева Д. Б. О знаках собственности у калмыков // Монголоведение в новом тысячелетии (к 170-летию организации первой кафедры монгольского языка в России). Мат-лы междунар. науч. конф. (г. Элиста, 22-26 сентября 2003 г.). Элиста: КалмГУ, 2003. 320 с.

Гедеева $2003 б-$ Гедеева Д. Б. О знаках «тамһ» и метках «им» как маркерах калмыцких родов // Монголоведение. Вып. 2. Элиста: АПП «Джангар», 2003. С. 272-275.

Городцов 1923- Городияов В. А. Археология. Т. 1. Каменный Период. М.; Петроград: Госиздат, 1923. $401 \mathrm{c}$.

Житецкий 1893 - Житеикий И. А. Очерки быта Астраханских калмыков. Этнографические наблюдения 1884-1886 гг. М.: Тип. М. Г. Волчанинова, 1893. 70 с.

Костенков 1868 - Калмыцкая степь Астраханской губернии по исследованиям Кумо-Манычской экспедиции под начальством К. И. Костенкова. СПб.: Тип. В. Безобразова и комп., 1868. 173 с.: ил.

Мезенцев 1969 - Мезенцев В. И. Фрагмент истории // В краю легенд и сказок. Элиста: Калм. кн. изд-во, 1969. 89 с.

Митиров 1998 - Митиров А. Г. Ойраты-калмыки: века и поколения. Элиста: Калм. кн. изд-во, 1998. 384 с.: ил.

Небольсин 1852 - Небольсин П. Очерки быта калмыков Хошоутовского улуса. СПб.: Тип. Карла Крайя, 1852. 190 с.

Позднеев 1911 - Позднеев А. М. Калмыцко-русский словарь. СПб.: Тип. Импер. Академии наук, $1911.306 \mathrm{c}$.

Пэрлээ 2012 - Пэрлээ Х. Бүтээлийн чуулган. Монгол түмний гарлыг хайж судлахнь 2 дахь хэвлэл (= Творческая конференция. Изучение истоков монгольского народа. 2-е изд). Улаанбаатар: Бэмби сан, 2012. 14 х.

Саруулбуян, Даваасамбуу 2008 - Саруулбуян Ж. Даваасамбуу А. Монголын адууны тамганы ойллого (= Заметки о монгольских лошадиных тамгах). Улаанбаатар: Бэмби Сан, 2008. 568 х.

Чойсамба 1974 - Чойсамба Д. Малын им, тамга. Түүний хууль цаазны ач холбогдол (= Метки «им» и «тамга» на животных. Их правовое значение). Улаанбаатар: Улсын хэвлэлийн газар. 1974. 133 х.

Шараева 2017 - Шараева Т. И. Этнические маркеры калмыков: исследования и материалы. Элиста: КалмНЦ РАН, 2017. 286 с.

\section{References}

[Kalmyk Steppe of Astrakhan Governorate: Reported Studies of the Kuma-Manych Research Expedition Led by Colonel K. I. Kostenkov]. St. Petersburg: V. Bezobrazov and Co., 1868. 173 p. (In Russ.)

Avlyaev G. O. [Origins of the Kalmyk People]. $2^{\text {nd }}$ ed., rev. and suppl. Elista: Kalmyk Book Publ., 2002. 325 p. (In Russ.)

Baasansükh Ya. [Present-Day Continuation of Mongolian Clan Tamgas]. Ulaanbaatar: Admon, 2008. 72 p. (In Mong.)

Bakaeva E. P. (Clan) Affiliation signs: tamgas of Mongolian Oirats and Kalmyks. In: [Cross-Border Culture: Comparative Studies in Traditions of Western Mongols and Kalmyks]. Monograph. E. P. Bakaeva et al. Elista: Kalmyk Scientific Center of RAS, 2016. Pp. 122-129. (In Russ.) 


\section{Этнология}

Batyreva S. G. [Kalmyk Folk Decorative and Applied Arts: $19^{\text {th }}-$ Early $20^{\text {th }}$ Centuries]. Elista: Dzhangar, 2006. 160 p. (In Russ.)

Beer R. The Encyclopedia of Tibetan Symbols and Motifs. L. Bubenkova (transl.). Moscow: Orientalia, 2011. 428 p. (In Russ.)

Beer R. The Handbook of Tibetan Buddhist Symbols. L. Bubenkova (transl.). Moscow: Orientalia, 2016. 336 p. (In Russ.)

Borisenko I., Moshuldaev B. [Khosheutovsky Khurul (Temple)]. Elista: Kalmyk Book Publ., 1989. 27 p. (In Russ.)

Choysamba D. ['Им' and 'Тамга' Animal Signs: Legal Meanings]. Ulaanbaatar: People's Publ., 1974. 133 p. (In Mong.)

Gedeeva D. B. About 'mash' signs and ' $u м$ ' markers. In: [Mongolian Studies]. Vol. 2. Elista: Dzhangar, 2003. Pp. 272-275. (In Russ.)

Gedeeva D. B. Kalmyk property signs revisited. In: [Mongolian Studies in the New Millennium]. Conf. proc. (Elista; September 22-26, 2003). Elista: Kalmyk State University, 2003. 320 p. (In Russ.)

Gorodtsov V. A. [Archaeology]. Vol. 1: Stone Age. Moscow; Petrograd: Gosizdat, 1923. 401 p. (In Russ.)

Mezentsev V. I. Fragment of history. In: [In the Land of Legends and Tales]. Elista: Kalmyk Book Publ., 1969. 89 p. (In Russ.)

Mitirov A. G. [Oirats-Kalmyks: Centuries and Generations]. Elista: Kalmyk Book Publ., 1998. 384 p. (In Russ.)

Nebolsin P. [Kalmyks of Khoshoutovsky District: Sketches of Everyday Life]. St. Petersburg: Karl Kray, 1852. 190 p. (In Russ.)

Perlee Kh. [Investigating Origins of the Mongolian Nation]. $2^{\text {nd }}$ ed. Ulaanbaatar: Bembi San, 2012. 14 p. (In Mong.)

Pozdneev A. M. [Kalmyk-Russian Dictionary]. St. Petersburg: Imperial Academy of Sciences, 1911. 306 p. (In Kalm. and Russ.)

Saruulbuyan Zh. Davaasambuu A. [Notes on Mongolian Horse Tamgas]. Ulaanbaatar: Bembi San, 2008. 568 p. (In Mong.)

Sharaeva T. I. [Kalmyk Ethnic Markers: Studies and Materials]. Elista: Kalmyk Scientific Center of RAS, 2017. 286 p. (In Russ.)

Zhitetsky I. A. [Astrakhan Kalmyks: Sketches of Everyday Life. Ethnographic Observations of 1884-1886]. Moscow: M. G. Volchaninov, 1893. 70 p. (In Russ.) 